Guan, S. S. A., Subrahmanyam, K., Linares, K., \& Cheng, R. (2015). Beauty in the eye of the beholder? Attractiveness in a virtual world. Cyberpsychology: Journal of Psychosocial Research on Cyberspace, 9(2), article 2. doi: 10.5817/CP2015-2-2

\title{
Beauty in the eye of the beholder? Attractiveness in a virtual world
}

\author{
Shu-Sha Angie Guan ${ }^{1}$, Kaveri Subrahmanyam², Kevin Linares ${ }^{3}$, Roy Cheng ${ }^{4}$ \\ ${ }^{1}$ California State University, Northridge, CA, United States \\ 2,4 California State University, Los Angeles, CA, United States \\ ${ }^{3}$ University of Illinois at Urbana-Champaign, IL, United States
}

\begin{abstract}
The current study examines whether traditional offline gender biases regarding physical attractiveness and status transfer to Second Life (SL), a virtual world where residents can easily manipulate the appearance and status of avatars (i.e., graphical representations of the self). Participants $\left(N=312,60.58 \%\right.$ female, $M_{a g e}=29.77, S D=10.53$ ) reported on demographics, SL usage, and rated the attractiveness of female and male avatars manipulated along physical attractiveness (high vs. low) and status (high vs. low). Mixed measures ANCOVAs were modeled separately for the female avatars and male avatars with withinsubjects factors (avatar characteristics: physical attractiveness and status) and betweensubject factors (participant characteristics: sex, and intensity of SL usage), while controlling for participant age. Consistent with offline norms, female avatars high in physical attractiveness were rated as more attractive, regardless of status. Participants rated male avatars high in physical attractiveness as more attractive if they were high in status compared to those low in status. We also found opposite-sex preferences and moderations by participant age and SL usage on avatar attractiveness ratings. The results suggest the continuity of offline gender norms and effect of in-world experience on perceptions of avatar appearance.
\end{abstract}

Keywords: Virtual worlds, avatars, attractiveness, status, gender norms

\section{Introduction}

Digital, online technologies have become central to our lives, especially among younger generations of youth (Lenhart, 2010). Additionally, millions of people worldwide visit and inhabit virtual communities, such as World of Warcraft EverQuest, and Second Life, where socialization can be a primary motivator to for continued play (Blinka \& Mikuška, 2014; Lo, 2008; Yee, 2006a, 2006b). Compared with face-to-face contexts, most virtual environments are not bound by offline space and time, and users can be as anonymous and disembodied as they wish. Consequently, users seem to be constructing and coconstructing online cultures and self-presentation within virtual communities (Boellstorff, 2008; Guitton, 2012; Linares, Subrahmanyam, Cheng \& Guan, 2011; Qiu, Lin \& Leung, 2012). The chat code of online teen chat rooms (Greenfield \& Subrahmanyam, 2003), "textisms" of electronic communication (Rosen, Chang, Erwin, Carrier \& Cheever, 2010), and the emerging truncated language of Twitter are just a few examples of the virtual culture created by a community of users.

At the same time, there appears to be some parallels between online and offline spaces. Research suggests that, although users are somewhat psychologically separated from their online selves and do conform to some online norms, most do not appear to be creating a completely different second self online (Linares et al., 2011). Many offline social behaviors and expectations, such as interpersonal distance conventions, altruism, and attractiveness stereotypes transfer into virtual environments (BehmMorawitz, 2013; Khan \& De Angeli, 2009; Merola \& Pena, 2009; Principe \& Langlois, 2013; Yee, Bailenson, Urbanek, Chang, \& Merget, 2007). Offline beliefs and standards of attractiveness may also be applied to online representations of the self in the form of avatars. These online attractiveness 
conventions may have important implications for interpersonal relationship formation, a primary motivation for virtual world residents (Lo, 2008).

\section{Second Life (SL) and Avatars}

$S L$ is a virtual environment that emphasizes interaction and creation, rather than conquest. Residents of $\mathrm{SL}$ experience their world through avatars, three-dimensional graphical representations of their online selves. Avatars are not bound by gravity or offline physical forms, so their physical features can be easily modified. These characteristics can also be altered at any point throughout the avatar's lifetime and residents report spending a lot of their time and money in-world to accumulate or purchase add-ons, such as skins and accessories (Boellstorff, 2008; Linares et al., 2011). Innovations in computer graphics have also resulted in highly realistic and human-like renderings of avatars (Giard \& Guitton, 2010).

Avatars are not unique to SL and are found in a variety of online contexts, and we draw on research from these different contexts to describe two possible connections between residents and their avatars. On the one hand, it has been suggested that, because avatars are physically separate from the body, users may create online representations that do not mirror their offline selves; instead, they choose socially idealized or alternate versions of the self (Gilbert et al., 2014; Huh \& Williams, 2010; Kendall, 1998; Smahel, Blinka, \& Ledabyl, 2008). In addition, as users adapt to the capacities and limitations of virtual environments, cultural learning of in-world social norms may make avatars appear less human and, therefore, less similar to their offline selves (Steen et al., 2006). The discrepancy between people and their online incarnations could mean that offline conventions may not transfer to online avatars. On the other hand, users may be psychologically connected to their avatars and even identify with them (BehmMorawitz, 2013; Vasalou \& Joinson, 2009); if this were the case, we would expect similarities between residents and their online avatars and avatar behavior. Research on SL avatar creation indicates that, although avatars come in a variety of forms-including human, vegetable, animal, and fantastical $-84 \%$ of SL residents reported having a primary avatar that was human and $56 \%$ reported modifying their avatar to resemble their offline self (Linares et al., 2011).

In addition to the potential for continuity between users and their online avatars, the standards and stereotypes embedded in larger sociopolitical contexts can also seep into online contexts (Boellstorff, 2008; Kendall, 1998; Lehdonvirta, Nagashima, Lehdonvirta, \& Baba, 2012; Palomares \& Lee, 2010; Yee et al., 2007). Past studies suggest that, much like offline appearance, avatar appearance matters when it comes to creating positive interactions online for youth and adults (Dehn \& Van Mulken, 2000; Messinger et al., 2008; Nowak \& Rauh, 2005; Principe \& Langlois, 2013; Yee, Bailenson, \& Ducheneaut, 2009). For example, Messinger et al. (2008) found that people who created SL avatars that were more attractive than their offline selves reported being more outgoing, extraverted, risk-taking, and loud online. Khan and De Angeli (2009) similarly found that avatars that were rated as more attractive were also perceived as more intellectually-, socially- and morally- competent. They were also preferred as social partners (Principe \& Langlois, 2013). Additionally, Yee et al. (2009) found that when users were assigned to taller avatars, they behaved more aggressively in a negotiation task. While height is often linked to competence offline, this aggressiveness in the online context is notable given that height is modifiable in virtual environments. The researchers also found that participants expected avatars that were rated as attractive, especially tall ones, to perform better in an online game. Taken together, it seems that, despite the unique online characteristics of avatars, some offline conventions regarding attractiveness and status (e.g., height) may carry over to the online world.

\section{Evaluating Others: Offline and Online Attractiveness and Status}

According to evolutionary psychological theory, physical features, such as symmetry, have become cultural cues of attractiveness, because they are signs of reproductive and genetic health (Buss, 1989; Jones et al., 2001; Perrett et al., 1998; Singh, 2006; Thornhill \& Gangestad, 2006; Waynforth, 2001). Additionally, body weight often correlates with ratings of attractiveness and health (Furnham, Swami, \& Shah, 2006). Evaluations of physical appearance and attractiveness play an important role in our offline lives including in social interactions. Physically attractive individuals are often judged to be more socially skilled, popular, and evaluated positively by others (Eagly, Ashmore, Makhijani, \& Longo, 1991; Feingold, 1992; Langlois et al., 2000).

Because of gendered norms within many cultures, these indicators of attractiveness differ for men and women (Buss, 1989; Buss et al., 2001). In a study of 37 cultures in 33 countries, Buss (1989) found that, when assessing a member of the opposite sex, men tend to place greater value on physical cues of fertility, such as an hourglass figure and youthful features, whereas women tend to place greater value on 
resource acquisition. That is, physical attractiveness may be a more salient marker when evaluating females. When evaluating males, higher status may be indicative of a stronger ability to gain resources, which in turn, increases attractiveness (Hickling, Noel, \& Yutzler, 1979). Cunningham, Barbee, and Pike (1990) found that men with high-status clothing were viewed as more attractive. Thus, cultural ornamentation (e.g. clothes, jewelry) can be indicators of potential resources and sexual fitness in the U.S. (Low, 1979).

Within SL, material displays on avatars (e.g., clothes, jewelry) can also serve as reference points for social and economic standing. Because SL currency (Linden dollars, L\$) has an exchange rate to United States dollars, there are economic and market forces within SL. Upon entering SL for the first time, new residents are able to choose from a variety of default avatars and options to customize features (e.g., shape, skin, hair). With time, residents can earn Linden dollars to further customize their avatars' appearances with clothes, jewelry, and other accessories. In fact, next to interacting with others, SL residents reported spending most of their in-world time modifying their avatars (Linares et al., 2011). Because there is no "leveling" up in $\mathrm{SL}$, as with some online games, symbols of status are primarily expressed through consumption and display patterns in-world much as in the offline world (Boellstorff, 2008) rather than performance grades found in online games (Lo, 2008). And much like adornments offline, digital accessories and clothing serve as cues for how avatars can be perceived (Merola \& Pena, 2009). Accordingly, a goal of this paper was to investigate whether or not these visual status markers (e.g., clothes, accessories) affect perceived attractiveness within SL as it does offline, especially when viewing male avatars.

\section{Digital Experience and Online Standards of Attractiveness}

From a sociocultural perspective, standards of beauty and status can be shaped, shared, and coconstructed within cultural contexts (Baumann, 2008; Furnham \& Alibhai, 1983; Greenfield, 1997; Swami \& Tovee, 2005). Swami and Tovee (2005), for example, found that Malaysian adults from rural areas found females with a higher body mass index (BMI) more attractive compared to Malaysian and British adults in urban areas. The authors suggest that these differences may be due to shifts in values influenced by the mass media showing more slim female figures as 'ideal' in urban areas and the maintained belief that body fat is an indicator of prosperity in more rural regions.

Like offline settings, online contexts have their own culture (Boellstorff, 2008; Greenfield, Gross, Subrahmanyam, Suzuki, \& Tynes, 2006; Qiu et al., 2012; Subrahmanyam, Smahel, \& Greenfield, 2006), and we expect that users similarly develop standards of beauty and status, which they apply while online. However, because different online contexts have different affordances (e.g., varying levels of anonymity or disembodiedness) and different interaction and socialization patterns within them, we expect that attractiveness and status are presented and perceived differently in different venues. Just as images in conventional media (e.g., television, films) provide information about cultural notions of attractiveness and unattractiveness in the offline world, SL avatars similarly offer SL residents slices of information about community attitudes, beliefs, and norms. Consequently, extensive experience in-world may shape judgments of the attractiveness of avatars by increasing the salience of contextualizing information (Khan \& De Angeli, 2009). It is also possible that time and interaction may simply improve impressions of avatars initially perceived as unattractive.

In addition to experience within the world of $\mathrm{SL}$, experience with the Internet and online graphics in general may also influence concepts of digital body and beauty. Empirical evidence suggests that mass media images play a large role in influencing social perceptions of attractiveness (e.g., Harrison, 1997), and it is likely that digital, online images similarly influence online perceptions of attractiveness. This may be especially true for youth, who have grown up immersed in digital media and have been named "digital natives" (Prensky, 2001). Compared with an older generation of "digital immigrants" who may or may not learn and adopt elements of technology, digital natives are believed to be fundamentally different in technological dependence and information processing (Palfrey \& Gasser, 2008; Prensky, 2001; Smahel et al., 2008; Tapscott, 1998). Therefore, it is possible that age as well as differences in digital media and virtual world experience may be related to perceptions of attractiveness as applied to SL avatars.

\section{The Present Study}

Whereas studies have explored the effect of avatar attractiveness on the behaviors of other users within a virtual context (Dehn \& Van Mulken, 2000; Messinger et al., 2008; Principe \& Langlois, 2013; Yee \& Bailenson, 2007), few studies have examined whether offline standards of attractiveness for male and females are applied to the construction and perception of online avatars. Khan and De Angeli (2009), for 
example, found that offline attractiveness stereotypes may be reproduced online among attractive, female avatars and that interaction with these avatars may moderate perceptions. However, this study did not examine other avatar characteristics such as gender or status. Lo (2008) found that avatar clothing and accessories that conveyed outward attractiveness and status can affect interpersonal attraction to (or desire to interact with) the avatar among online gamers. However, this study did not examine the interaction between avatar characteristics and user characteristics (e.g., sex, age, virtual world experience). We extend this work by exploring the interaction of physical attractiveness and status for perceptions of attractiveness among both male and female avatars in a popular virtual world. And given that social constructions of beauty are dynamic (Buss, Shackelford, Kirkpatrick, \& Larsen, 2001), often transformed by offline historic and personal development as well as the norms of specific online contexts, we also examine how individual user characteristics such as sex, age, and experience within a context moderate perceptions.

Hypothesis 1a. Given that the literature on offline cultural constructions of attractiveness suggests that physical beauty is more salient an indicator of attractiveness for females (Buss, 1989; Hickling et al., 1979), we expect that physical attractiveness manipulations of female avatars will have an effect on attractiveness ratings.

Hypothesis 1b. Additionally, given that this research suggests status may be more pertinent in judgements of males, we expect that status manipulations of male avatars will influence attractiveness ratings.

Hypothesis 2. Prior research also suggests that attractiveness and status cues may be more pertinent to opposite-sex judgments of attractiveness. Therefore, we further expect that attractiveness manipulations of female avatars will have a greater effect on male perceivers and status manipulations of male avatars will especially influence attractiveness ratings among female perceivers.

Hypothesis 3. Additionally, because younger individuals may have more digital experience and may be more acculturated to media, we hypothesize that younger adults will rate avatars as more attractive than older adults.

Hypothesis 4. However, age may not be the only acculturating factor. Time spent in a virtual world, online norms, and co-constructions of meaning with other users may also be internalized and affect perceptions of attractiveness (Khan \& De Angeli, 2009; Steen et al., 2006; Subrahmanyam et al., 2006; Zhou, 2011). Consequently, we hypothesize that greater familiarity with SL will also be associated with increased perceived attractiveness of avatars.

\section{Method}

\section{Participants}

Participants $\left(N=312,60.58 \%\right.$ female) ranged in age from 18 to 69 years $\left(M_{\text {age }}=29.77, S D=10.53\right)$. Most reported that they lived in North America (56.1\%) and Europe (24.2\%), followed by South America $(11.0 \%)$, Asia $(8.3 \%)$, and Africa $(.4 \%)$. Self-reported SL usage varied from those who had never been on SL (our non-SL user group, $n=42, M_{\text {age }}=20.19, S D=3.52$ ), those who spent less than 1 hour to 3 hours when signed onto $S L\left(n=124, M_{\text {age }}=31.39, S D=10.57\right), 4$ to 9 hours $\left(n=115, M_{\text {age }}=31.40, S D\right.$ $=10.18)$, and 10 or more hours $\left(n=28, M_{a g e}=31.32, S D=11.55\right)$. Only participants who reported a heterosexual orientation were included in the analyses given that the prior literature on attractiveness has mostly focused on opposite-sex relationships.

\section{Procedure}

This study was part of a larger study on the attitudes and behaviors in the virtual world of SL (Linares et al., 2011). Participants completed an online survey including questions about their SL experiences and avatars. SL resident participants were recruited through advertisements in-world and via discussion groups on Facebook and Craigslist. The postings contained a link to an online survey hosted by SurveyMonkey.com. After completing a consent form, participants answered questions about their SL experience and the avatar stimuli. At the end of the study, participants who indicated that they wanted to receive compensation were paid 300 Linden dollars (US $\$ 1.50$ at the time of the study) in-world. Non-SL users were recruited from a diverse university in Los Angeles through the psychology subject pool. They were only included in the study if they were over 18 years of age (the minimum age to register a SL account) and reported that they had never been in SL. 


\section{Measures}

Demographics. Participants reported on their demographic information, such as age, country of residence, sex, and sexual orientation.

Intensity of SL usage. The SL group was asked about their intensity of SL usage (i.e., "How much time do you spend on SL each time you sign on?") on a scale ranging from 1 (less than 1 hour) to 6 (open all the time).

Avatar ratings. Participants were presented with screenshots of the avatar stimuli and asked to rate them on attractiveness ("How attractive is this avatar?") on a scale of 1 very unattractive to 5 very attractive and status ("Please rate the status of this avatar") on a scale of 1 very low status to 5 very high status.

\section{Stimuli Creation}

The avatar stimuli were manipulated on two dimensions: status and physical attractiveness. As a result, as shown in Figures 1 and 2, we had four categories of each of the female and male avatar prototypes: high in status and physical attractiveness $(\mathrm{HH})$, high in status and low in physical attractiveness (HL), low in status and high in physical attractiveness (LH), and low in status and physical attractiveness (LL).

When users enter SL for the first time, they are able to choose from a number of pre-made, default avatars and make modifications in physical attractiveness characteristics (e.g., facial features and body size) and status objects (e.g., accessories/ornamentation like clothes, jewelry) that have been shown to be indicators of and linked to attraction in prior studies of virtual users (Khan \& De Angeli, 2009; Lo, 2008; Merola \& Pena, 2009). It is important to note that the default avatars were created using an earlier version of SL.

The avatars used in this study were made by modifying the shape/size, skin, facial measurements, hair, and attire of the default human avatars. Shape/size in SL comprised of height, body proportion (i.e., muscle, body fat), weight status, as well as irregular body modifications, such as short or long arms. Popular SL shapes were purchased from in-world stores, along with male and female skins. Stores were selected based on popularity as measured by foot traffic (i.e., frequency of unique IP addresses from SL users visiting a host server per day/week) during the week prior to creation.

The attractive avatar's shapes were kept consistent after applying the purchased shapes, from here on out known as the baseline shape, while the low attractive avatars were modified based on scalable height (e.g., shorter than the baseline height), body thickness and fat (e.g., higher waist and hip circumference along with increased chest and neck body proportion), and jaw/facial structure (e.g., roundness of the jaw line accompany by more facial fat) dimensions. The purchased skin that accompanied the baseline shape was used on all four stimuli to keep the skin tone constant. Attire included clothing along with shoes, glasses, and jewelry that was purchased from popular in-world stores using the same criteria mentioned above. For low status avatars, clothes that came with the default avatars known as "freebie" clothes were used. For high status avatars, items and clothes purchased with SL Lindens were used. The differences between purchased and freebie clothes and accessories were the quality of texture (i.e., more realistic print) and object size (i.e., creating a better 'fit' on an avatar). Hair design is unique in SL, as users can select type of hair texture, color, length, and style. Since brunettes represent the larger majority of human hair color (Rich \& Cash, 1993; Sorokowski, 2008; Swami \& Barrett, 2011), hair color was kept constant (i.e., brunette) among the avatars.

Our changes were informed by our ethnographic observations and unstructured interviews with SL residents about dimensions of avatar attractiveness. Several male and female prototype avatars with modifications were created. A focus group of four research assistants and male and female in-world SL users familiar with the study but not with the hypotheses ranked the avatars in human likeness, how standard they were in $\mathrm{SL}$, and attractiveness in order to identify the most prototypical male and female avatar in the four categorizations of interest $(\mathrm{HH}, \mathrm{HL}, \mathrm{LH}, \mathrm{LL})$. 
High Status

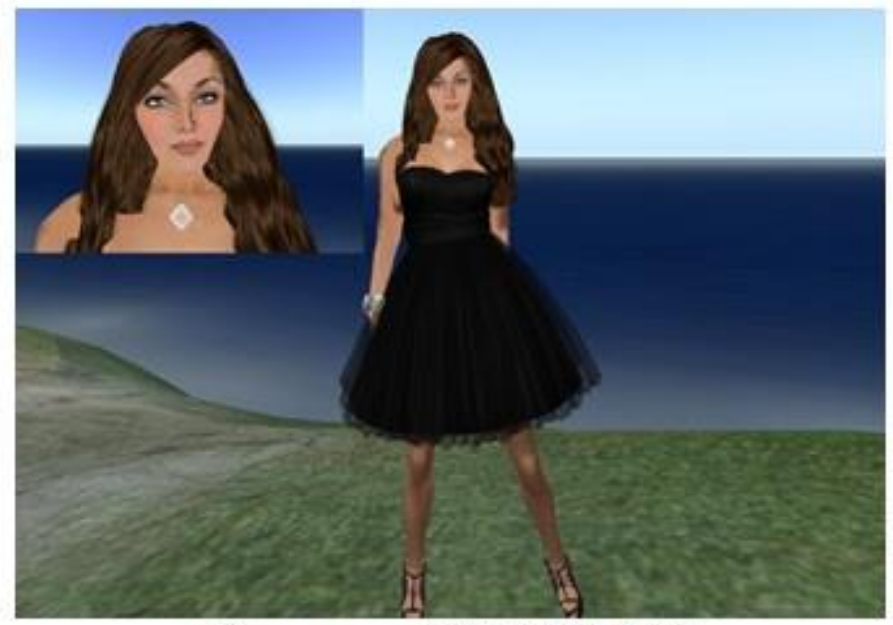

$M_{\text {attractiveness }}(S D)=3.74(.95)$

$M_{\text {stotus }}(S D)=3.70(.85)$

\section{Low Physical Attractiveness}

High Status

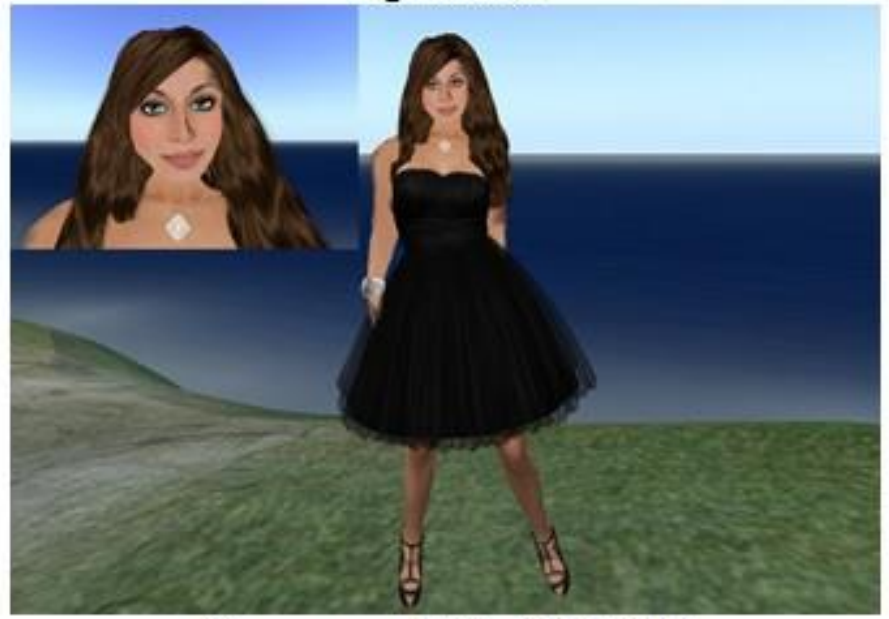

$M_{\text {ottroctiveness }}(S D)=3.24(.99)$

$M_{\text {stotus }}(S D)=3.52(.86)$
Low Status

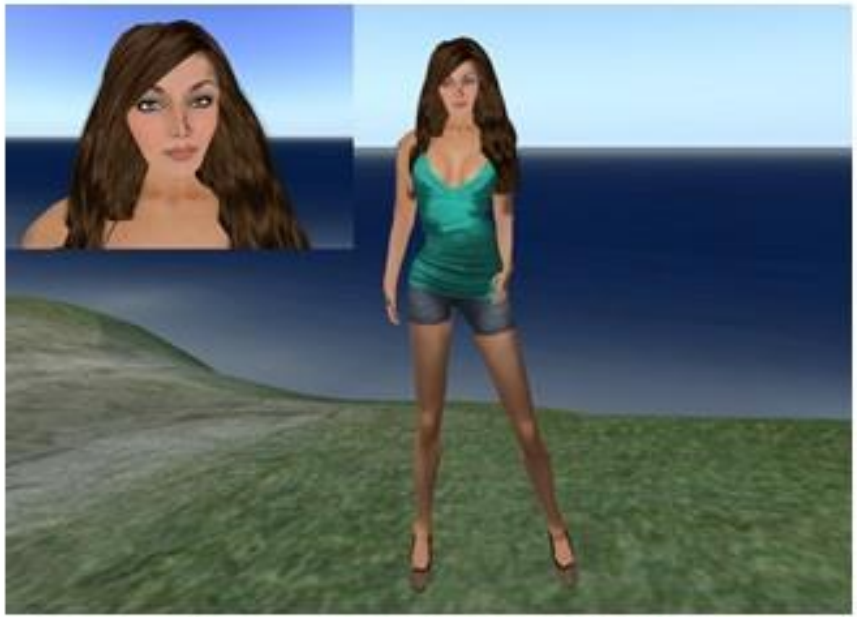

Mattractiveness $(S D)=3.65(.91)$

$M_{\text {stotus }}(S D)=3.31(.84)$

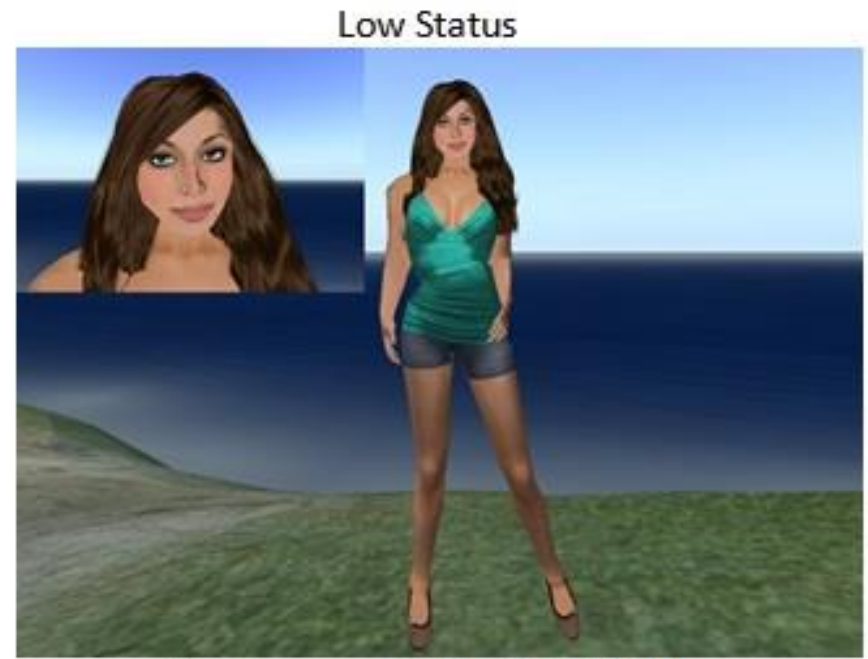

$M_{\text {ottractiveness }}(S D)=3.30(1.02)$

$M_{\text {stotus }}(S D)=3.05(.84)$

Figure 1. Female avatar stimuli by physical attractiveness and status condition with average attractiveness and status rating. 
High Status

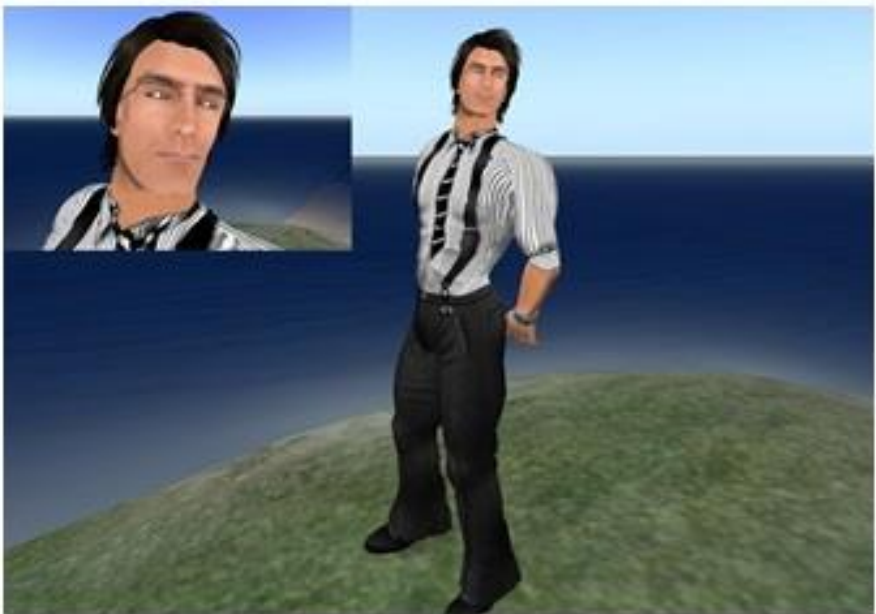

Mottractiveness $(S D)=3.55$ (1.07)

$M_{\text {stotus }}(S D)=3.76(.96)$

\section{Low Physical Attractiveness}

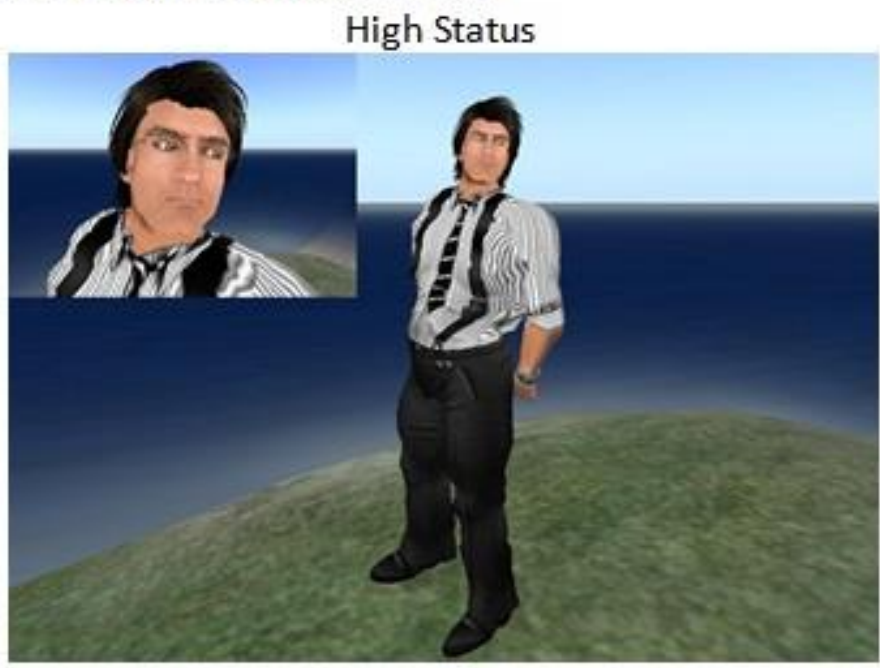

Mottroctiveness $(S D)=2.33(.94)$

$M_{\text {stotus }}(S D)=2.83(.95)$
Low Status

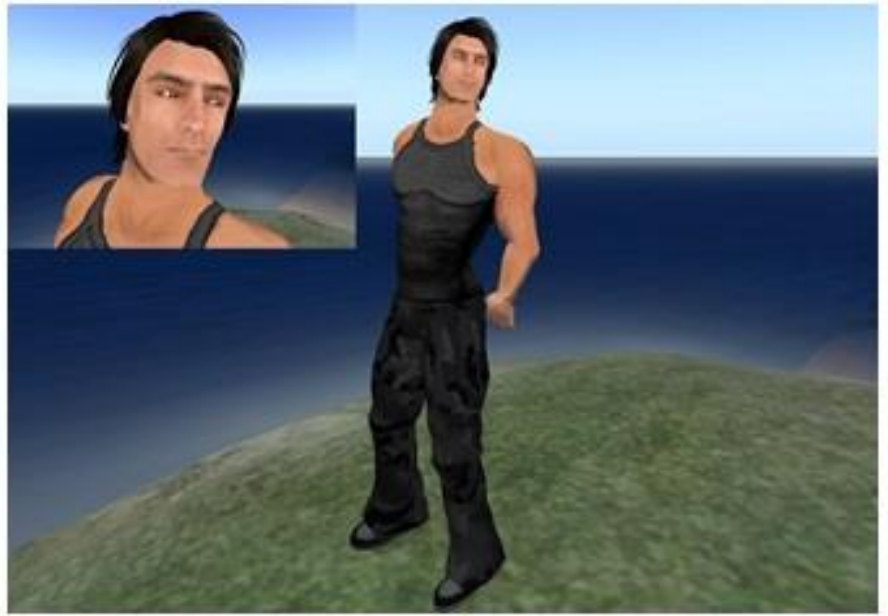

Mattractiveness $(S D)=2.92(.95)$

$M_{\text {stotus }}(S D)=2.79(.76)$

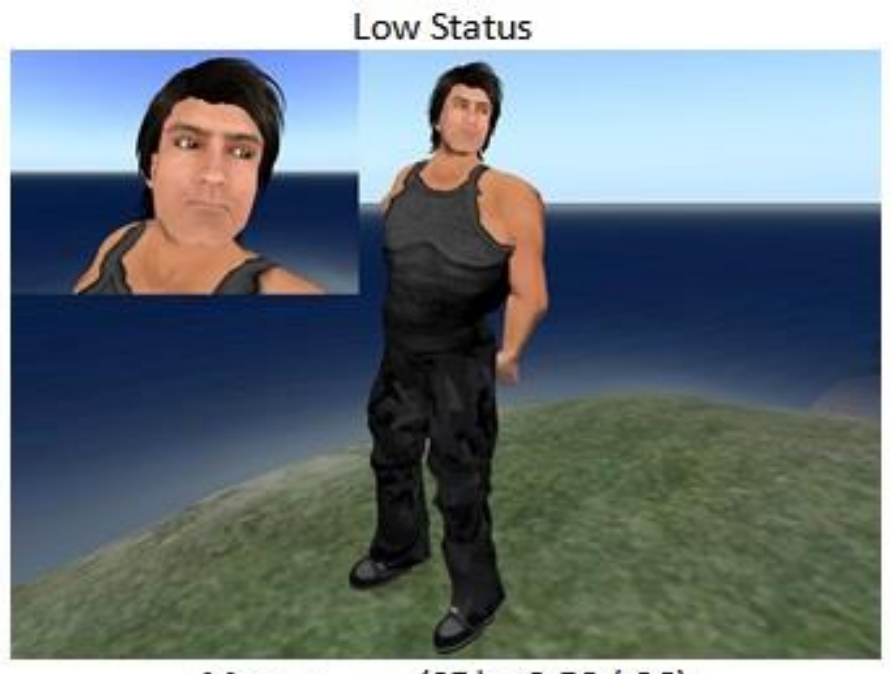

Mattractiveness $(S D)=2.50(.96)$

$M_{\text {stotus }}(S D)=2.23(.83)$

Figure 2. Male avatar stimuli by physical attractiveness and status condition with average attractiveness and status rating.

\section{Results}

\section{Manipulation Check}

A 2x2 repeated measures ANOVA confirmed our intuitions about the avatars' physical attractiveness and status: both male and females avatars in the high physical attractiveness category were rated as more attractive than those in the low physical attractiveness category, $F s(1,292-294)=325.83,95.22, p s<$ .001. Similarly, both male and female avatars created in the high status category were rated as significantly higher in status by participants than those in the low status category, $F s(1,274-292)=$ $281.09,90.58, p s<.001$. Figures 1 and 2 show the average attractiveness and status rating for each avatar.

\section{Hypotheses Testing}

To examine attractiveness ratings among the different categories of avatars, mixed measures ANCOVAs were modeled separately for the female avatars (Table 1) and male avatars (Table 2) with avatar characteristics (avatar physical attractiveness [High, Low] and status [High, Low]) as within-subject 
factors. Participant characteristics such as sex and intensity of SL usage were between-subjects factors and age was the covariate. The interaction of avatar characteristics (attractiveness, status) and participant characteristics (sex, age, and SL usage) were also included in the models.

Table 1. Mixed Measures Analysis of Variance Assessing Brunette, Female Avatar Attractiveness by Target and Perceiver Characteristics.

\begin{tabular}{|c|c|c|c|}
\hline Avatar Characteristics & $\boldsymbol{F}$ & $p$ & $\eta^{2}$ \\
\hline \multicolumn{4}{|l|}{ (Within Subjects) } \\
\hline Physical Attractiveness & 32.72 & $<.001$ & .11 \\
\hline Status & .25 & $n s$ & - \\
\hline \multicolumn{4}{|l|}{$\begin{array}{l}\text { Perceiver Characteristics } \\
\text { (Between Subjects) }\end{array}$} \\
\hline Age & 3.02 & ns & - \\
\hline Gender & 4.94 & .03 & .02 \\
\hline SL Usage & 1.75 & ns & - \\
\hline \multicolumn{4}{|l|}{ Interactions } \\
\hline Physical Attractiveness x Age & 7.98 & .005 & .03 \\
\hline $\begin{array}{l}\text { Physical Attractiveness x } \\
\text { Gender }\end{array}$ & .60 & ns & - \\
\hline $\begin{array}{l}\text { Physical Attractiveness x SL } \\
\text { Usage }\end{array}$ & .74 & ns & - \\
\hline Status $\times$ Age & .92 & ns & - \\
\hline Status x Gender & 2.14 & ns & - \\
\hline Status x SL Usage & 7.76 & $<.001$ & .08 \\
\hline $\begin{array}{l}\text { Physical Attractiveness } \mathrm{x} \\
\text { Status }\end{array}$ & 3.50 & ns & - \\
\hline
\end{tabular}

Table 2. Mixed Measures Analysis of Variance Assessing Male Avatar Attractiveness by Target and Perceiver Characteristics.

\begin{tabular}{lrcc}
\hline Avatar Characteristics & $\boldsymbol{F}$ & $\boldsymbol{p}$ & $\boldsymbol{\eta}^{\mathbf{2}}$ \\
\hline (Within Subjects) & & & \\
$\quad$ Physical Attractiveness & 95.46 & $<.001$ & .26 \\
$\quad$ Status & 9.83 & $<.01$ & .03 \\
Perceiver Characteristics & & & \\
(Between Subjects) & 13.88 & $<.01$ & .02 \\
$\quad$ Age & 3.84 & $n s$ & - \\
$\quad$ Gender & 3.43 & .02 & .04 \\
SL Usage & & & \\
Interactions & 25.42 & $<.001$ & .08 \\
$\quad$ Physical Attractiveness x Age & 15.91 & $<.001$ & .05 \\
$\quad$ Physical Attractiveness x & & & \\
Gender & 8.25 & $<.001$ & .08 \\
Physical Attractiveness x SL & & & - \\
$\quad$ Usage & 3.05 & $n s$ & .02 \\
Status x Age & 5.15 & .02 & - \\
$\quad$ Status x Gender & .99 & $n s$ & .09 \\
$\quad$ Status x SL Usage & 27.36 & $<.001$ & \\
Physical Attractiveness x & & & \\
$\quad$ Status & & & \\
\hline
\end{tabular}




\section{Hypothesis 1a: Is Physical Attractiveness More Salient Than Status When Judging Female Avatars?}

The results shown in Table 1 indicate that female avatars high in physical attractiveness were rated as more attractive $(M=3.69, S D=.83)$ than those low in physical attractiveness $(M=3.27, S D=.89)$. There was no main effect of status on ratings for female avatars.

\section{Hypothesis 1b: Is Status More Salient Than Physical Attractiveness in Judgments Of Male Avatars?}

As shown in Table 2, there was a main effect of physical attractiveness and status for male avatars. There was also a significant interaction between physical attractiveness and status (Figure 3a). Follow-up paired t-tests indicated that, for male avatars high in physical attractiveness, those that were also high in status were rated as more attractive $(M=3.56, S D=1.06)$ than those low in status $(M=2.92, S D=.95)$, $t(296)=10.25, p<.001$. However, for male avatars low in physical attractiveness, those who were high in status were rated less attractive $(M=2.33, S D=.94)$ compared to those low in status $(M=2.50, S D$ $=.97), t(294)=-3.04, p<.01$.

\section{Hypothesis 2: Are Physical Appearance and Status Preferences More Salient For the Opposite-Sex?}

Female avatars. The results in Table 1 also indicate that there was an effect of participant sex, such that males rated female avatars as significantly more attractive $(M=3.63, S D=1.71)$ than female participants $(M=3.42, S D=1.61)$. There were no interactions between the manipulation categories and participant sex.

Male avatars. There was an interaction of physical attractiveness and status by participant sex (Figure $3 \mathrm{~b}, 3 \mathrm{c})$. Follow-up analyses indicated that male avatars high in physical attractiveness were rated as more attractive by female $(M=3.35, S D=.82)$ than male participants $(M=3.03, S D=.88), t(292)=-3.14, p$ $<.01$. Male and female participants did not differ in their ratings of male avatars low in attractiveness, $t(291)=.27$, $n s$. Status differences showed a similar pattern, and female participants rated male avatars high in status as more attractive $(M=3.02, S D=.78)$ than male participants $(M=2.79, S D=.78)$, $t(292)=-2.39, p<.05$, male and female participants did not differ in their ratings of male avatars low in status, $t(291)=-.68, n s$.

(a)

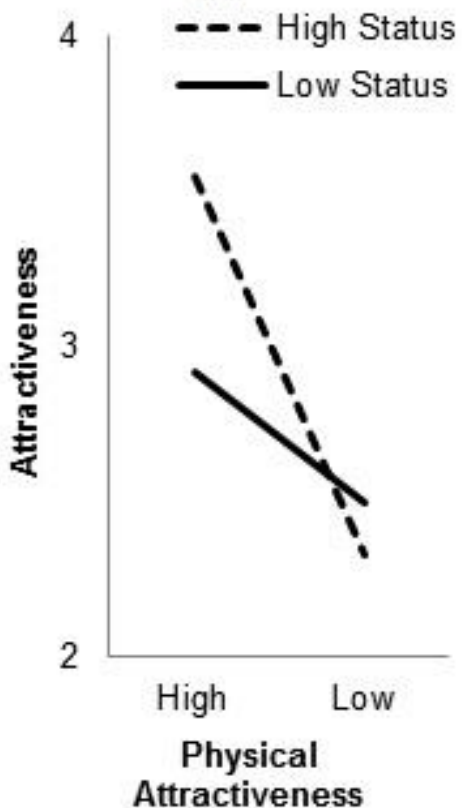

(b)
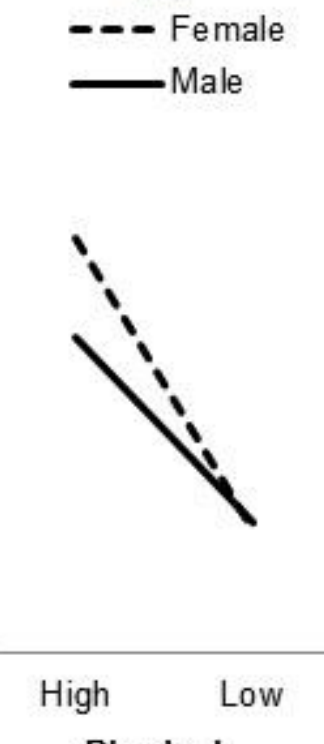

Physical Attractiveness (c)
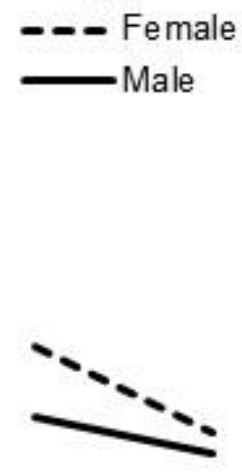

High Low

Status

Figure 3. Interactions by participant characteristics and avatar conditions for male avatars. 


\section{Hypothesis 3: Are Physical Appearance and Status Preferences More Salient For Younger Adults Compared to Older Adults?}

Female avatars. There was a significant interaction of physical attractiveness and age. Follow-up regression models controlling for gender and SL usage revealed that age was not associated with attractiveness ratings for female avatars high in physical attractiveness $(b=.003, \mathrm{SES}=.005, p=.50)$ regardless of status. However, age positively predicted attractiveness ratings for female avatars low in physical attractiveness $(b=.014, S E=.005, p=.005)$ regardless of status.

Male avatars. There was a significant interaction of physical attractiveness and age. Follow-up regression models controlling for gender and SL usage revealed that age was not associated with attractiveness ratings for male avatars high in physical attractiveness $(b=.007$, SEs $=.005, p=.16)$ regardless of status. However, age positively predicted attractiveness ratings for male avatars low in physical attractiveness $(b=.023, S E=.004, p>.001)$ regardless of status.

\section{Hypothesis 4: How Does Intensity of SL Usage Affect Participant Judgments of Avatar Attractiveness?}

Non-SL users $(M=20.19, S D=31.27)$ were younger compared to the $S L$ users $((M=31.27, S D=$ $10.47), t(309)=-6.79, p<.001$. However, there were no significant differences in age across the SL usage groups, $F(2,263)=.001, p=.999$.

Female avatars. There was an interaction between SL usage and status (Figure 4a). Follow-up ANOVA analyses with Bonferroni corrections indicated that participants with no SL experience (the non-SL group) rated female avatars low in status as more attractive $(M=3.77, S D=.90)$ than those high in status $(M=$ $3.42, S D=1.61)$. There were no significant differences in ratings of participants with SL experience, $\operatorname{ts}(26-117)=.93-1.74$, ns.

Male Avatars. While there was a main effect of SL usage, there was also an interaction between SL usage and physical attractiveness (Figure 4b). Follow-up Bonferroni comparisons $(p=.05)$ of the four SL groups showed that participants at the extreme ends of usage (non-SL user group and SL users who spent 10 hours or more when they signed onto $\mathrm{SL}$ ) generally gave lower ratings to avatars high in physical attractiveness compared to moderate SL usage groups (SL users who spent 1-3 hours and those who 4-9 hours in-world), $F(3,293)=6.96, p<.001$. There were no significant group differences in the ratings for avatars low in physical attractiveness, $F(3,292)=1.29$, ns.

\section{Female Avatar}

(a)

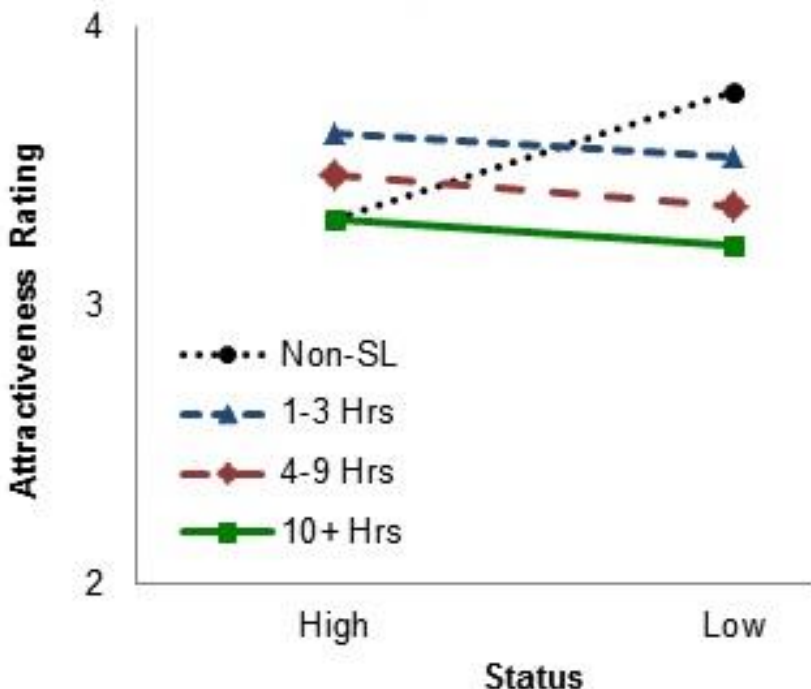

Male Avatar

(b)

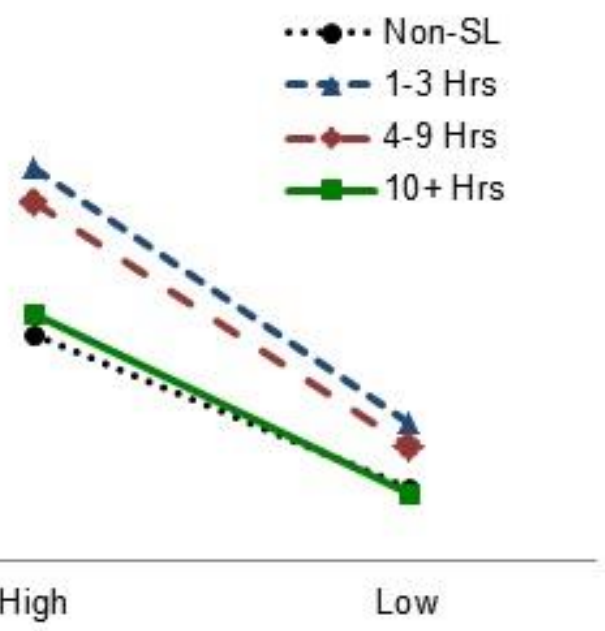

Physical Attractiveness

Figure 4. Interactions of intensity of SL usage by status and physical attractiveness for female and male avatars. 


\section{Discussion}

We undertook this study to examine whether offline conventions regarding attractiveness would transfer to judgments of avatars within Second Life, a virtual world. In support of our hypothesis that important offline markers of attractiveness (e.g., status for men) would be applied online, the current study found that status manipulations had an effect on participants' judgments of male avatars, but not female avatars. Additionally, consistent with research on offline opposite-sex preferences (Bailenson \& Beall, 2006; Buss, 1989; Cunningham et al., 1990; Hickling et al., 1979), we found that female avatars were rated as more attractive overall by male than female participants. Also in line with this literature, female participants tended to rate male avatars with some advantage, either in high attractiveness or status, as more attractive than male participants. Interestingly, male and female participants did not differ in their low ratings of male and female avatars low in physical attractiveness and status. It seems that, just as in the offline world, low status and attractiveness were liabilities that were not easily compensated for within the online context.

Also, we found that higher status only had an effect on male avatars high in attractiveness (rather than for all male avatars across the board). The boost from attractiveness may be indicative of emerging 'metrosexual' norms, in which men as well as women are expected to be image-conscious consumers of fashion and beauty products. This can be magnified in online contexts where perhaps physical attractiveness is more salient due to its disembodied nature. Thus, online physical appearance seems to matter for both males and females. However, despite past work that showed the online context may be more empowering for females (e.g., Hilbert, 2011; Smahel \& Subrahmanyam, 2007), it may not be the great equalizer. Our results suggest that online representations and perceptions of females online may still be tied to offline norms. That is, there is continuity in the importance of physical attractiveness for females.

Contrary to our predictions regarding the importance of gendered attractiveness cues by age, older participants gave higher attractiveness ratings for avatars in the low physical attractiveness category. This finding is inconsistent with prior work that has found no differences across age (Principe \& Langlois, 2013). However, in the prior work, young children (age 6 - 10) were compared with young adult undergraduates and only facial attractiveness was examined. In the current study, we examined an older age range and included full-body stimuli that may include more sexual cues relevant to attractiveness judgements among adults. One possible reason for the results found here may be that greater digital experience may make users more accustomed to online community standards and thus more discerning of graphic images. Another possibility is that, while some ideals of attractiveness are persistent across generations (Baker-Sperry \& Grauerholz, 2003; Rich \& Cash, 1993), others may experience social shift (Buss et al., 2001; Lamb, Jackson, Cassiday, \& Priest, 1993). That is, physical appearance manipulations for male and female avatars in the present study, confirmed through a focus group of undergraduate research assistants, may not accurately reflect an older generation's perceptions of attractiveness (e.g., in body shape). It should be noted that the attractiveness manipulation included size as a criteria and, thus, attractiveness could have been confounded with weight. Although lower weight has been associated with attractiveness in research studies (Furnham et al., 2006), older individuals may be more accepting and find a wider range of body types attractive. Additionally, weight may serve as a visual cue for age, which can also influence attractiveness (e.g., Lennon, 1988).

Lastly, given the burgeoning independence, sexual maturity, and focus on romantic partnering during this transitional stage (Arnett, 2000), young adults may be more attuned to and discerning of physical attributes and social constructions of attractiveness. Thornhill and colleagues (2003), for example, found that younger women especially preferred symmetry, a sign of attractiveness and health in men, compared to older women. Previous studies have also found that, while individuals of all ages showed some agreement in judgments of attractiveness, older participants were generally less negative in attractiveness ratings than younger participants (Henss, 1991; Perlini, Bertolissi, \& Lind, 1999). Future research should examine whether this age difference in perceptions of avatars is attributable to increased experience with technology, a cohort effect, or a developmental effect.

Along similar lines and based on prior research (Khan \& De Angeli, 2009), we hypothesized that SL experience would be associated with avatar attractiveness ratings. However, there seemed to be a nonlinear trend whereby moderate SL users (SL users who spent either 1 to 3 hours or 4 to 9 hours in SL each time they signed on) gave higher ratings to physically attractive male avatars than participants in groups at the extreme ends of usage (the non-SL usage group and SL users who spent 10 or more hours in $\mathrm{SL}$ each time they signed on). Whereas the non-SL user group was younger in age, age was not significantly different across the SL user groups. This suggests that age was not driving differences 
between the high and low SL users. Although the non-SL user group and the most intense SL user group seemed to be in agreement here, there may be different mechanisms driving their ratings.

Similar to younger users, SL users who spend a great deal of time in-world may be the most accustomed to avatar graphics and have greater opportunities to acquire contextualized information. Another possibility is that their increased intensity of usage may put them at the end of the cultural learning and mastery curves. This increased familiarity with SL conventions and possible desensitization may have contributed to the disconnect between the online and offline that we found in high intensity SL users (Khan \& De Angeli, 2009; Steen et al., 2006).

As for the non-SL user group, their ratings of female avatars may provide some explanation for these differences. In contrast to all participants with SL experience, non-SL users rated female avatars in the low status category as more attractive than those in the high status category. Given that our non-SL user group was recruited at a university, lack of experience with the Internet is not likely an explanation. Rather, the opposite-than-expected trend in the non-SL user group is perhaps an indication that SL status signals were not read in the same way and may have to be learned through in-world experience. To our non-SL group, the avatars might have appeared simply as graphic images imitating human forms. While studies on the detrimental or desensitizing effects of media violence and static images of beauty are abundant, there is little research on how experience in interactive, online contexts with dynamic images changes our perceptions of attractiveness (see Khan \& De Angeli, 2009 for exception). The effect of virtual world experience needs further examination given the growing prevalence of these Internet communities.

Notably, across the analyses, we saw the most variability in attractiveness ratings in male avatars. This is consistent with the claim that, because physical attractiveness is more highly valued in females than males in most cultures, there would be greater agreement in evaluations of women than men (Giard \& Guitton, 2010; Langlois et al., 2000; Townsend \& Wasserman, 1997). Additionally, while masculine features can be associated with attractiveness, it can also denote negative traits, such as dominance or coldness (Penton-Voak, Jacobson, \& Trivers, 2004; Perrett et al., 1998). Appearing to care about or greatly modifying appearances may also be discordant with notions of masculinity, although this may be in flux (Pompper, 2010).

In sum, we explored the degree of psychological distance between the physical and digital worlds by examining the potential replication of offline cultural norms to the online. The results suggest that there seems to be transfer from one context into the other but that some norms may be more parallel (such as the importance of physical attractiveness for females) than others (such as with the variability within ratings of male attractiveness). It has been argued that the lack of cues in computer-mediated communication can increase depersonalization (Herring, 1993; Yates, 1997). This depersonalization can lead to greater psychological distance, which can in turn, lead to increases in antisocial behaviors in nonface-to-face interactions and perhaps fragmented identities. However, as we found here, individuals often find ways to adapt to the constraints of online environments in ways that make it analogous to a 'phantom limb,' a non-physical part of oneself, within a digital context (Turkle, 2011). In this sense, the online culture would mirror that of the offline as we carry these beliefs and expectations into digital domains, as has been shown by other researchers (Linares et al., 2011; Qiu et al., 2012; Yee et al., 2009).

Although these findings add to the literature on online experiences, this study had a few limitations. We specifically chose SL because it was less 'game-like' and emphasized social interaction. Indeed, one of the strengths of the study was to examine attractiveness as well as status in an online environment that mirrors real life in emphasizing social interaction and commerce. However, it is only one of several virtual worlds, and it is unknown whether the results found here will generalize to other virtual contexts. Also, because SL is interactive, residents shape their own experiences. Those who spend more time on certain activities, like shopping or modifying their avatars, may be more susceptible to the influence of in-world attractiveness norms. On a related note, because this is a cross-sectional study of averaged ratings across unequally-sized usage groups, the interpretations of the effect of age and SL experience on perceptions of attractiveness would benefit from a longitudinal approach, and the analysis of ratings over time would better examine the possible causal role of individual differences and digital experience.

Characteristics of our stimuli are also limitations to generalizability. Because we wanted to reduce the number of confounds, the range of features on our avatar stimuli were limited and only participants who reported they were heterosexual were included in the analyses to control for differing biases in attractiveness ratings. Additionally, our avatars varied in clothing and, therefore, level of skin exposure. In particular, for the female avatars, the low status avatars revealed more skin and cleavage for avatars 
in both the low and high physical attractiveness conditions. Prior research, for example, has found that female avatars do often reveal more skin than male avatars which may affect perceptions of sexuality and attractiveness (Lomanowska \& Guitton, 2012). However, despite exposing more skin, the low status female avatars were not rated as more attractive. Also, although SL graphics have improved in the last few years, some features like facial hair on male avatars remains more difficult to render. Future studies should examine and carefully control the influence of other factors or features affecting attractiveness, such as body type, hair color, skin color, skin exposure, facial hair and texture that also carry social information (Giard \& Guitton, 2010; Sorokowski, 2008; Swami \& Barrett, 2011; Swami et al., 2008), to gain a better understanding of how the complex notion of gendered attractiveness is manipulated and interpreted in a virtual world.

Lastly, it is possible that participants are rating the status of users (who are able to purchase accessories like glasses, jewelry, etc.) rather than avatars per se. However, this is less likely given that SL users, our population of interest, can have multiple avatars and, more importantly, recognize that other users often have multiple avatars (Linares et al., 2011). These avatars may represent different facets of users, look different, be used with varying frequency, and users may invest different amounts of resources in them. Therefore, although there is a connection between SL residents and their avatars, we don't believe that our SL participants made a strong connection from avatar to owner.

Despite these limitations, the study described in this paper suggests that some offline norms of attractiveness for men and women may function in similar ways in evaluations of online male and female self-presentations. Although some researchers theorize that the lack of physical cues in computermediated interactions may reduce discrimination and biases, also known as 'the democratic theory' (Herring, 1993; Yates, 1997), we found that offline gendered preferences are reproduced in perceptions of digital world forms disconnected from physical bodies. As previously discussed, there is evidence that, while aspects of self and cultural standards may be lost in the translation into online mediums, there is also a connection between offline and online norms, identity, and self-presentation (Subrahmanyam \& Greenfield, 2008; Subrahmanyam et al., 2006). Attractiveness conventions are one cultural element that may transfer from offline contexts to online ones and, thus, may shed light on processes of cultural transfer between offline and online worlds. Individuals often use different strategies to create a particular impression and invoke a positive response from others (Goffman, 1959). Just as attractiveness matters in the offline, it also seems to influence others in the online. Given the affordances of the digital media context, manipulation of physical appearance may be an especially useful non-verbal tool through which to create likeability and intimacy with others (Walther, 1996).

Our findings suggest continuity between the offline and online found in prior research (Linares et al., 2011; Subrahmanyam et al., 2006; Yee et al., 2007). Furthermore, individual characteristics such as digital familiarity may moderate online perceptions. Given the growing use of online communities for recreation as well as education and the relation of online avatars and offline behaviors (Behm-Morawitz, 2013; Merola \& Pena, 2009), it would be worthwhile for future research to examine the implications of these replicated norms to contexts where avatars are used and on how users choose avatars. As society, commerce, and Internet technologies grow more interdependent, our study provides insight into how our perceptions of self and others may persist or change within a digital context.

\section{Acknowledgement}

This work was supported by the Foundation for Psychocultural Research and University of California, Los Angeles Center for Culture, Brain, and Development (FPR-UCLA CBD) and the Minority Biomedical Research Support-Research Initiative for Scientific Enhancement (MBRS-RISE) Program at California State University, Los Angeles.

\section{References}

Arnett, J. J. (2000). Emerging adulthood: A theory of development from the late teens through the twenties. American Psychologist, 55, 469-480.

Bailenson, J. N., \& Beall, A. C. (2006). Transformed social interaction: Exploring the digital plasticity of avatars. Avatars at Work and Play, 1-16.

Baker-Sperry, L., \& Grauerholz, L. (2003). The pervasiveness and persistence of the feminine beauty ideal in children's fairy tales. Gender \& Society, 17, 711-726. http://dx.doi.org/10.1177/0891243203255605 
Baumann, S. (2008). The moral underpinnings of beauty: A meaning-based explanation for light and dark complexions in advertising. Poetics, 36(1), 2-23. http://dx.doi.org/10.1016/j.poetic.2007.11.002

Behm-Morawitz, E. (2013). Mirrored selves: The influence of self-presence in a virtual world on health, appearance, and well-being. Computers in Human Behavior, 29, 119-128.

http://dx.doi.org/10.1016/j.chb.2012.07.023

Blinka, L., \& Mikuška, J. (2014). The role of social motivation and sociability of gamers in online game addiction. Cyberpsychology: Journal of Psychosocial Research on Cyberspace, 8(2), article 6.

http://dx.doi.org/10.5817/CP2014-2-6

Boellstorff, T. (2008). Coming of age in Second Life: An anthropologist explores the virtually human. Princeton, NJ: Princeton University Press.

Buss, D. M. (1989). Sex differences in human mate preferences: Evolutionary hypotheses tested in 37 cultures. Behavioral and Brain Sciences, 12(1), 1-49. http://dx.doi.org/10.1017/S0140525X00023992

Buss, D. M., Shackelford, T. K., Kirkpatrick, L. A., \& Larsen, R. J. (2001). A half century of mate preferences: The cultural evolution of values. Journal of Marriage and Family, 63, 491-503.

http://dx.doi.org/10.1111/j.1741-3737.2001.00491.x

Cunningham, M. R., Barbee, A. P., \& Pike, C. L. (1990). What do women want? Facialmetric assessment of multiple motives in the perception of male facial physical attractiveness. Journal of Personality and Social Psychology, 59, 61-72. http://dx.doi.org/10.1037/0022-3514.59.1.61

Dehn, D. M., \& Van Mulken, S. (2000). The impact of animated interface agents: a review of empirical research. International Journal of Human-Computer Studies, 52, 1-22.

http://dx.doi.org/10.1006/ijhc.1999.0325

Eagly, A. H., Ashmore, R. D., Makhijani, M. G., \& Longo, L. C. (1991). What is beautiful is good, but...: A meta-analytic review of research on the physical attractiveness stereotype. Psychological Bulletin, 110, 109-128. http://dx.doi.org/10.1037/0033-2909.110.1.109

Feingold, A. (1992). Good-looking people are not what we think. Psychological bulletin, 111, 304-341. http://dx.doi.org/10.1037/0033-2909.111.2.304

Furnham, A., \& Alibhai, N. (1983). Cross-cultural differences in the perception of female body shapes. Psychological Medicine, 13, 829-837. http://dx.doi.org/10.1017/S0033291700051540

Furnham, A., Swami, V., \& Shah, K. (2006). Body weight, waist-to-hip ratio and breast size correlates of ratings of attractiveness and health. Personality and Individual Differences 41, 443-454.

http://dx.doi.org/10.1016/j.paid.2006.02.007

Giard, F., \& Guitton, M. J. (2010). Beauty or realism: The dimensions of skin from cognitive sciences to computer graphics. Computers in Human Behavior 26, 1748-1752.

http://dx.doi.org/10.1016/j.chb.2010.07.001

Gilbert, R., Thadani, V., Handy, C., Andrews, H., Sguigna, T., Sasso, A., \& Payne, S. (2014). The psychological functions of avatars and alt (s): A qualitative study. Computers in Human Behavior 32, 1-8. http://dx.doi.org/10.1016/j.chb.2013.11.007

Goffman, E. (1959). The presentation of self in everyday life. New York: Doubleday Anchor.

Grammer, K., \& Thornhill, R. (1994). Human (Homo sapiens) facial attractiveness and sexual selection: the role of symmetry and averageness. Journal of Comparative Psychology, 108, 233-242.

http://dx.doi.org/10.1037/0735-7036.108.3.233

Greenfield, P. M., Gross, E. F., Subrahmanyam, K., Suzuki, L. K., \& Tynes, B. (2006). Teens on the Internet: Interpersonal connection, identity, and information. In R. E. Kraut, M. Brynin, \& S. Kiesler (Eds.), Computers, Phones, and the internet: Domesticating information technology (pp. 185-200). New York, NY: Oxford University Press. 
Greenfield, P. M., \& Subrahmanyam, K. (2003). Online discourse in a teen chatroom: New codes and new modes of coherence in a visual medium. Journal of Applied Developmental Psychology, 24, 713-738. http://dx.doi.org/10.1016/j.appdev.2003.09.005

Guitton, M. J. (2012). Living in the hutt space: Immersive process in the star wars role-play community of second life. Computers in Human Behavior 28, 1681-1691. http://dx.doi.org/10.1016/j.chb.2012.04.006

Harrison, K. (1997). Does interpersonal attraction to thin media personalities promote eating disorders? Journal of Broadcasting \& Electronic Media, 41, 478-500. http://dx.doi.org/10.1080/08838159709364422

Henss, R. (1991). Perceiving age and attractiveness in facial photographs. Journal of Applied Social Psychology, 21, 933-946. http://dx.doi.org/10.1111/j.1559-1816.1991.tb00451.x

Herring, S. (1993). Gender and democracy in computer mediated communication. Electronic Journal of Communication, 3(2).

Hickling, E. J., Noel, R. C., \& Yutzler, F. D. (1979). Attractiveness and occupational status. The Journal of Psychology, 102, 71-76. http://dx.doi.org/10.1080/00223980.1979.9915096

Hilbert, M. (2011). Digital gender divide or technologically empowered women in developing countries? A typical case of lies, damned lies, and statistics. Women's Studies International Forum, 34, 479-489.

http://dx.doi.org/10.1016/j.wsif.2011.07.001

Huh, S., \& Williams, D. (2010). Dude looks like a lady: Gender swapping in an online game. In W. S. Bainbridge (Ed.), Online worlds: Convergence of the real and the virtual (pp. 161-174). London, UK: Springer.

Jones, B. C., Little, A. C., Penton-Voak, I. S., Tiddeman, B. P., Burt, D. M., \& Perrett, D. I. (2001). Facial symmetry and judgements of apparent health: Support for a "good genes" explanation of the attractiveness-symmetry relationship. Evolution and Human Behavior, 22, 417-429.

http://dx.doi.org/10.1016/S1090-5138(01)00083-6

Kendall, L. (1998). Meaning and identity in "cyberspace": The performance of gender, class, and race online. Symbolic Interaction, 21, 129-153. http://dx.doi.org/10.1525/si.1998.21.2.129

Khan, R., \& De Angeli, A. (2009). The attractiveness stereotype in the evaluation of embodied conversational agents. In T. Gross, J. Gulliksen, P. Kotze, L. Ostreicher, P. Palanque, R. O. Prates, \& M. Winckler (Eds.), Human-computer interaction-INTERACT 2009 (Vol. 5726, pp. 85-97). Berlin: Springer.

Lamb, C. S., Jackson, L. A., Cassiday, P. B., \& Priest, D. J. (1993). Body figure preferences of men and women: A comparison of two generations. Sex Roles, 28, 345-358.

http://dx.doi.org/10.1007/BF00289890

Langlois, J. H., Kalakanis, L., Rubenstein, A. J., Larson, A., Hallam, M., \& Smoot, M. (2000). Maxims or myths of beauty? A meta-analytic and theoretical review. Psychological bulletin, 126, 390-423.

Lehdonvirta, M., Nagashima, Y., Lehdonvirta, V., \& Baba, A. (2012). The stoic male: How avatar gender affects help-seeking behavior in an online game. Games and Culture, 7(1), 29-47.

Lenhart, A. (2010). Social media \& mobile internet use among teens and young adults: Pew Research Center.]

Lennon, S. J. (1988). Physical attractiveness, age, and body type. Home Economics Research Journal, 16, 195-203. http://dx.doi.org/10.1177/1077727X8801600304

Linares, K., Subrahmanyam, K., Cheng, R., \& Guan, S. S. A. (2011). A Second Life within Second Life: Are virtual world users creating new selves and new lives? International Journal of Cyber Behavior, Psychology and Learning, 1(3), 50-71. http://dx.doi.org/10.4018/ijcbpl.2011070104 
Lo, S.-K. (2008). The impact of online game characteristics outward attractiveness and social status on interpersonal attraction. Computers in Human Behavior, 24, 1947-1958.

http://dx.doi.org/10.1016/j.chb.2007.08.001

Lomanowska, A. M., \& Guitton, M. J. (2012). Virtually naked: Virtual environment reveals sex-dependent nature of skin disclosure. PloS one 7(12), e51921. http://dx.doi.org/10.1371/journal.pone.0051921

Low, B. S. (1979). Sexual selection and human ornamentation. Evolutionary Biology and Human Social Behavior, 1979, 462-487.

Merola, N., \& Pena, J. (2009). The effects of avatar appearance in virtual worlds. Journal for Virtual Worlds Research, 2(5).

Messinger, P. R., Ge, X., Stroulia, E., Lyons, K., Smirnov, K., \& Bone, M. (2008). On the relationship between my avatar and myself. Journal of Virtual Worlds Research, 1(2), 1-17.

Nowak, K. L., \& Rauh, C. (2005). The influence of the avatar on online perceptions of anthropomorphism, androgyny, credibility, homophily, and attraction. Journal of Computer-Mediated Communication, 11, 153178. http://dx.doi.org/10.1111/j.1083-6101.2006.tb00308.x

Palfrey, J., \& Gasser, U. (2008). Born digital: Understanding the first generation of digital natives. New York, NY: Basic Books.

Palomares, N. A., \& Lee, E. J. (2010). Virtual gender identity: the linguistic assimilation to gendered avatars in computer-mediated communication. Journal of Language and Social Psychology, 29, 5-23. http://dx.doi.org/10.1177/0261927X09351675

Penton-Voak, I. S., Jacobson, A., \& Trivers, R. (2004). Populational differences in attractiveness judgements of male and female faces: Comparing British and Jamaican samples. Evolution and Human Behavior, 25, 355-370. http://dx.doi.org/10.1016/j.evolhumbehav.2004.06.002

Perlini, A. H., Bertolissi, S., \& Lind, D. L. (1999). The effects of women's age and physical appearance on evaluations of attractiveness and social desirability. The Journal of social psychology, 139, 343-354. http://dx.doi.org/10.1080/00224549909598390

Perrett, D. I., Lee, K. J., Penton-Voak, I., Rowland, D., Yoshikawa, S., Burt, D. M., . . Akamatsu, S. (1998). Effects of sexual dimorphism on facial attractiveness. Nature, 394, 884-887.

http://dx.doi.org/10.1038/29772

Pompper, D. (2010). Masculinities, the metrosexual, and media images: Across dimensions of age and ethnicity. Sex roles, 63, 682-696. http://dx.doi.org/10.1007/s11199-010-9870-7

Prensky, M. (2001). Digital natives, digital immigrants. On the horizon, 9(5), 1-6.

Principe, C. P., \& Langlois, J. H. (2013). Children and adults use attractiveness as a social cue in real people and avatars. Journal of experimental child psychology, 115, 590-597.

http://dx.doi.org/10.1016/j.jecp.2012.12.002

Qiu, L., Lin, H., \& Leung, A. K. (2012). Cultural differences and switching of in-group sharing behavior between an American (Facebook) and a Chinese (Renren) social networking site. Journal of Cross-Cultural Psychology, 1-16.

Rich, M. K., \& Cash, T. F. (1993). The American image of beauty: Media representations of hair color for four decades. Sex Roles, 29, 113-124. http://dx.doi.org/10.1007/BF00289999

Rosen, L. D., Chang, J., Erwin, L., Carrier, L. M., \& Cheever, N. A. (2010). The relationship between "textisms" and formal and informal writing among young adults. Communication Research, 37, 420-440. http://dx.doi.org/10.1177/0093650210362465

Singh, D. (2006). Universal allure of the hourglass figure: an evolutionary theory of female physical attractiveness. Clinics in Plastic Surgery, 33, 359-370. 
Smahel, D., Blinka, L., \& Ledabyl, O. (2008). Playing MMORPGs: Connections between addiction and identifying with a character. CyberPsychology \& Behavior 11, 715-718.

http://dx.doi.org/10.1089/cpb.2007.0210

Smahel, D., \& Subrahmanyam, K. (2007). "Any girls want to chat press 911": Partner selection in monitored and unmonitored teen chat rooms. CyberPsychology \& Behavior, 10, 346-353.

http://dx.doi.org/10.1089/cpb.2006.9945

Sorokowski, P. (2008). Attractiveness of blonde women in evolutionary perspective: studies with two Polish samples. Perceptual and Motor Skills, 106, 737-744.

Steen, F. F., Greenfield, P. M., Davies, M. S., Tynes, B., Vorderer, P. E., \& Bryant, J. E. (2006). What went wrong with The Sims Online: Cultural learning and barriers to identification in a massively multiplayer online role-playing game. In P. Vorderer \& J. Bryant (Eds.), Playing video games: Motives, responses, and consequences (pp. 307-324). Mahwah, NJ: Lawrence Erlbaum Associates.

Subrahmanyam, K., \& Greenfield, P. M. (2008). Media symbol systems and cognitive processes. In S. L. Calvert \& B. J. Wilson (Eds.), The Handbook of Children, Media and Development. Boston, MA: Blackwell.

Subrahmanyam, K., Smahel, D., \& Greenfield, P. M. (2006). Connecting developmental constructions to the internet: identity presentation and sexual exploration in online teen chat rooms. Developmental Psychology, 42(3), 395. http://dx.doi.org/10.1037/0012-1649.42.3.395

Swami, V., \& Barrett, S. (2011). British men's hair color preferences: An assessment of courtship solicitation and stimulus ratings. Scandinavian Journal of Psychology, 52, 595-600.

http://dx.doi.org/10.1111/j.1467-9450.2011.00911.x

Swami, V., Furnham, A., \& Joshi, K. (2008). The influence of skin tone, hair length, and hair colour on ratings of women's physical attractiveness, health and fertility. Scandinavian Journal of Psychology, 49, 429-437. http://dx.doi.org/10.1111/j.1467-9450.2008.00651.x

Swami, V., \& Tovee, M. J. (2005). Female physical attractiveness in Britain and Malaysia: A cross-cultural study. Body Image, 2, 115-128. http://dx.doi.org/10.1016/j.bodyim.2005.02.002

Tapscott, D. (1998). Growing up digital: The rise of the net generation. New York, NY: McGraw-Hill Companies.

Terdiman, D. (2007, July 10, 2012). Counting the real "Second Life' population. Retrieved from: http://news.cnet.com/Counting-the-real-Second-Life-population/2100-1043_3-6146943.html

Thornhill, R., \& Gangestad, S. W. (2006). Facial sexual dimorphism, developmental stability, and susceptibility to disease in men and women. Evolution and Human Behavior, 27, 131-144.

http://dx.doi.org/10.1016/j.evolhumbehav.2005.06.001

Thornhill, R., Gangestad, S. W., Miller, R., Scheyd, G., McCollough, J. K., \& Franklin, M. (2003). Major histocompatibility complex genes, symmetry, and body scent attractiveness in men and women.

Behavioral Ecology, 14, 668-678. http://dx.doi.org/10.1093/beheco/arg043

Townsend, J. M., \& Wasserman, T. (1997). The perception of sexual attractiveness: Sex differences in variability. Archives of Sexual Behavior, 26, 243-268. http://dx.doi.org/10.1023/A:1024570814293

Turkle, S. (2011). Alone together: Why we expect more from technology and less from each other. New York, NY: Basic Books.

Vasalou, A., \& Joinson, A. N. (2009). Me, myself and I: The role of interactional context on selfpresentation through avatars. Computers in Human Behavior, 25, 510-520.

http://dx.doi.org/10.1016/j.chb.2008.11.007

Walther, J. B. (1996). Computer-mediated communication impersonal, interpersonal, and hyperpersonal interaction. Communication research, 23, 3-43. http://dx.doi.org/10.1177/009365096023001001 
Waynforth, D. (2001). Mate choice trade-offs and women's preference for physically attractive men. Human Nature, 12, 207-219. http://dx.doi.org/10.1007/s12110-001-1007-9

Yates, S. J. (1997). Gender, identity and CMC. Journal of Computer Assisted Learning, 13, 281-290. http://dx.doi.org/10.1046/j.1365-2729.1997.00031.x

Yee, N. (2006a). The demographics, motivations, and derived experiences of users of massively multiuser online graphical environments. Presence: Teleoperators and Virtual Environments, 15, 309-329.

Yee, N. (2006b). Motivations for play in online games. CyberPsychology \& Behavior, 9, 772-775. http://dx.doi.org/10.1089/cpb.2006.9.772

Yee, N., \& Bailenson, J. (2007). The Proteus Effect: The Effect of Transformed Self Representation on Behavior. Human Communication Research, 33, 271-290. http://dx.doi.org/10.1111/j.1468-

2958.2007.00299.x

Yee, N., Bailenson, J. N., \& Ducheneaut, N. (2009). The Proteus effect implications of transformed digital self-representation on online and offline behavior. Communication Research, 36, 285-312.

http://dx.doi.org/10.1177/0093650208330254

Yee, N., Bailenson, J. N., Urbanek, M., Chang, F., \& Merget, D. (2007). The unbearable likeness of being digital: The persistence of nonverbal social norms in online virtual environments. CyberPsychology \& Behavior, 10, 115-121. http://dx.doi.org/10.1089/cpb.2006.9984

Zhou, T. (2011). Understanding online community user participation: a social influence perspective. Internet Research, 21,67-81. http://dx.doi.org/10.1108/10662241111104884

\section{Correspondence to:}

Shu-Sha Angie Guan

California State University, Northridge

Child and Adolescent Development

18111 Nordhoff Street, Northridge, CA 91330

United States

Email: angiesguan(at)gmail.com 


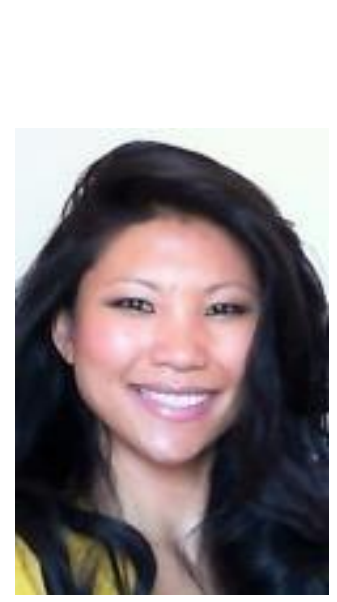

\begin{abstract}
About authors
Shu-Sha Angie Guan, PhD, is an Assistant Professor of Child and Adolescent Development at California State University, Northridge. She is interested in the social, psychological and physical implications of digital media among diverse populations, including ethnic minorities and immigrants. She can be reached at

angie.guan(at)csun.edu
\end{abstract}

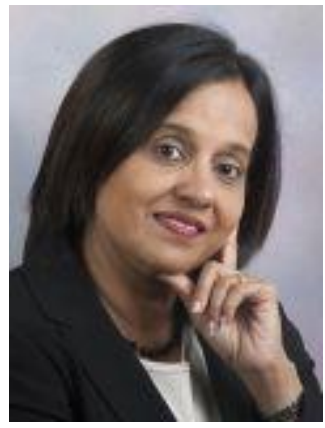

Kaveri Subrahmanyam, $\mathrm{PhD}$, is Professor of Psychology at California State University, Los Angeles and Associate Director of the Children's Digital Media Center @ Los Angeles. She studies the cognitive and social implications of interactive media use and is currently researching the daily use of interactive media among youth as well as the academic and cognitive implications of multitasking. Dr. Subrahmanyam has published several research articles on youth and digital media and co-edited a special section on interactive media and human development for Developmental Psychology (2012) and a special issue on social networking for the Journal of Applied Developmental Psychology (2008). She is the co-author (with David Smahel) of Digital Youth: The Role of Media in Development (Springer, 2011). She can be reached at ksubrah(at)calstatela.edu

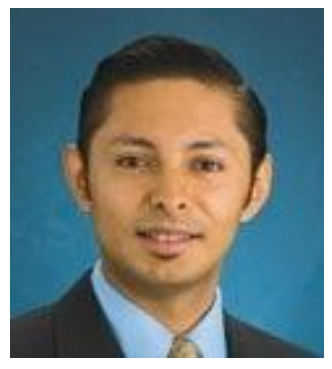

Kevin A. Linares, MA, is a doctoral student in the department of Human and Community Development at the University of Illinois at Urbana-Champaign. He is interested in understanding the social and economic implications of military service for the adaptation process of children of immigrants. He can be reached at klinares(at)illinois.edu

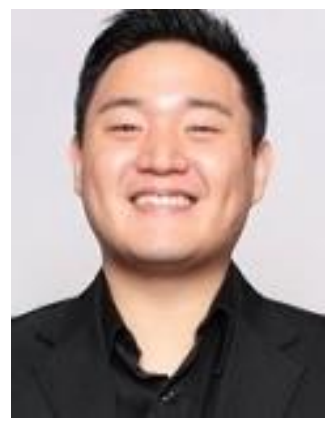

Roy Cheng, MSc/MA, is a researcher at Lieberman Research Worldwide. He manages an array of international quantitative and qualitative projects to gain consumer insights for strategic business development. His work focuses on toys and games, entertainment, and banking/finance. He can be reached at rcheng(at)Irwonline.com 